\title{
The Drosophila endocycle is controlled by Cyclin E and lacks a checkpoint ensuring S-phase completion
}

\author{
Mary A. Lilly and Allan C. Spradling \\ Howard Hughes Medical Institute Research Laboratories, Carnegie Institution of Washington, \\ Baltimore, Maryland 21210 USA
}

Early during Drosophila oogenesis the 16 interconnected cells of each germ-line cyst choose between two alternative fates. The single future oocyte enters meiosis, arrests, and becomes transcriptionally quiescent. The remaining 15 cells initiate a series of polyploid cell cycles to prepare for their role as nurse cells. Like many other polyploid and polytene cells, during nurse cell growth the major satellite DNAs become highly under-represented by a mechanism that has remained obscure. We implicate the cell-cycle regulator $c y c l i n E$ in DNA under-representation by identifying a hypomorphic, female sterile $c y c E$ mutation, $c y c E^{01672}$, that increases the amount of satellite DNA propagated in nurse cells. In mutant but not wild-type endomitotic nurse cells, "late $S$ " patterns of bromodeoxyuridine incorporation are observed similar to those in mitotic cells. CycE protein still cycles in $c y c E^{01672}$ germ-line cysts but at reduced levels, and it is found throughout a longer fraction of the cell cycle. Our experiments support the view that oscillating levels of CycE control the polyploid S phase. Moreover, they indicate that a checkpoint linking the presence of unreplicated DNA to the CycE oscillator is lacking, leading to incomplete replication of late-replicating sequences such as satellite DNAs. Unexpectedly, two to three of the 16 cells in $c y c E^{01672}$ cysts frequently differentiate as oocytes, implicating cell-cycle programming in oocyte determination.

[Key Words: Endocycle; cyclin E; checkpoint; oocyte determination]

Received July 3, 1996; revised version accepted August 19, 1996.

Recent studies of cell-cycle control provide a framework for examining the developmental regulation of the cell cycle. Cell proliferation is dependent on the ordered completion of two events during the mitotic cell cycle: replication of the genome in $\mathrm{S}$ phase and segregation of duplicate genomes in mitosis. Checkpoints make sure that each event, DNA replication or chromosome segregation, is correctly completed before the next event is initiated (for review, see Nurse 1994). The obligate alternation of $S$ phase and $M$ phase ensures that the ploidy of mitotic cells remains constant. However, in many organisms, including Drosophila melanogaster, a developmentally programmed endoreplicative cycle decouples DNA replication from mitosis /see Smith and OrrWeaver 1991). Endocycling cells undergo successive rounds of DNA replication without an intervening mitosis and develop large, polyploid nuclei. The checkpoint controls that ensure that $S$ phase and $M$ phase alternate in the mitotic cycle are dependent on the activity of cdc2 and the mitotic cyclins (Broek et al 1991; Hayles et al. 1994; Moreno and Nurse 1994; Sauer et al. 1995). In

${ }^{1}$ Corresponding author.
Drosophila, cyclin A, cyclin B, and cdc2 are not required for embryonic endoreplication (Lehner and O'Farrell 1990b; Whitfield et al. 1990; Stern et al. 1993). Only the $G_{1}$ cyclin, cyclin $E$, has been shown to function in endoreplicating cells (Knoblich et al. 1994; Duronio and O'Farrell 1995), where it associates with the cdk2 homolog, Dmcdc2c (Lehner and O'Farrell 1990a; Sauer et al. 1995).

Cyclin $\mathrm{E}$ forms an active complex with the cyclindependent kinase cdk2 and plays a key role in the transition from $G_{1}$ into $S$ phase (Dulic et al. 1992; Koff et al. 1992). In proliferating mammalian cells the over-expression of cyclin E shortens $\mathrm{G}_{1}$ /Ohtsubo and Roberts 1993; Resnitzky et al. 1994). In Drosophila, DmcycE (cycE) has been shown to be necessary for the $G_{1}-S$ transition in cycle 17 of embryogenesis (Knoblich et al. 1994). In addition, ectopic expression of CycE can induce cells to inappropriately or prematurely enter $\mathrm{S}$ phase (Knoblich et al. 1994; Richardson et al. 1995). Interestingly, the regulation of CycE expression is different in the endomitotic versus mitotic cycles. In the endocycle, $\mathrm{CycE}$ down regulates its own expression, providing a possible mechanism for the cyclic regulation of the endocycles (Duronio and O'Farrell 1995; Sauer et al. 1995). 
In the mitotic cycle, the replication of the entire genome in $S$ phase is a prerequisite to the initiation of mitosis and subsequent cell division (for review, see Heichman and Roberts 1994). In contrast, the copy number per haploid genome (representation) of numerous sequences changes in many endocycling cells. For example, many polyploid and polytene cells contain greatly reduced amounts of DNAs residing in heterochromatic regions (Heitz 1934; for review, see Spradling and OrrWeaver 1987), including DNA satellites (Gall et al. 1971) and rDNAs (Hennig and Meer 1971). In eukaryotes, genomes are replicated in temporally distinct intervals of the S phase (reviewed in Hand 1978). DNAs residing within heterochromatic chromosome regions typically initiate replication relatively late in S phase and continue replicating after other regions have finished, giving rise to a distinct period very late in $S$ phase that can be visualized as a spatially restricted pattern of bromodeoxyuridine (BrdU) incorporation (Nakamura et al. 1986). Therefore, one possible explanation for the under-representation of heterochromatic sequences in polyploid nuclei is that late DNA replication is bypassed in the endocycle. However, very little has been learned about the temporal programming of $\mathrm{S}$ phase in either mitotic or endomitotic cells.

Oogenesis in Drosophila provides an excellent system for analyzing the developmental regulation of the mitotic and endomitotic cell cycles (for review, see Mahowald and Kambysellis 1980; Spradling 1993). Egg production takes place within 16-cell germ-line cysts (Fig. 1A). New cysts are formed by a fixed series of asymmetric, incomplete divisions that link each cell to its neighbors through one to four intercellular bridges known as ring canals. After cyst completion, one of the two cells possessing four ring canals begins to accumulate the cyst cell centrioles (Mahowald and Strassheim 1970) as well as specific gene transcripts (e.g., Kim-Ha et al. 1991; Suter and Steward 1991) that are transported through the ring canals from the other 15 cells. The receiving cell subsequently differentiates as an oocyte, whereas the transporting cells become nurse cells. Disruption of intercellular transport by mutations in Bic-D (Suter and Steward 1991), egl (Suter and Steward 1991), hts (Yue and Spradling 1992), or stonewall (Clark and McKearin 1996) or by cholchicine treatments (Koch and Spitzer 1983; Theurkauf et al. 1993) interfere with oocyte determination. After cyst formation, the nurse cells immediately exit the mitotic cycle and begin a series of 10-12 endocycles. Each germ-line cyst becomes enveloped by 15-20 somatic follicle cells, which first divide mitotically to form an overlying monolayer of $\sim 800$ cells, and then carry out four to five polyploid cell cycles. The major satellite DNAs become under-represented in both polyploid nurse and follicle cells (Hammond and Laird 1985). However, the reductions are less extensive in germ linederived nurse cells than in somatic polyploid cells in several insect species, including Drosophila (Zacharias 1979; Hammond and Laird 1985; Nazimiec and Beckingham 1986).

The differentiation of nurse cells and an oocyte within
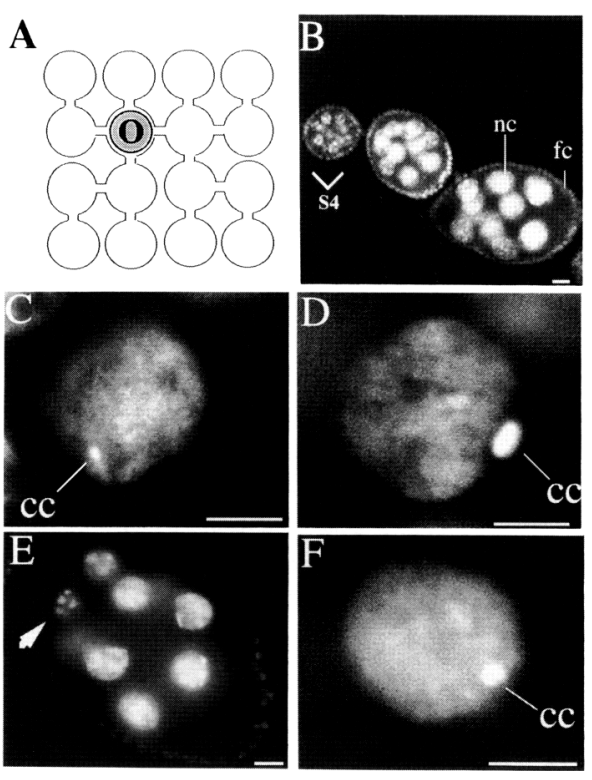

Figure 1. $f_{s}(2) 01672$ alters nurse cell nuclear organization. $(A)$ Structure of a 16-cell germ-line cyst, showing the differing number of ring canals joining individual cells. $(O)$ Oocyte. $(B)$ Developmental changes in nurse cell nuclear structure (DAPI staining). Note the relatively large number of follicle cells compared with nurse cells. (nc) Nurse cell; (fc) follicle cell; (S4) stage 4 egg chamber with blob-like chromosomes. Wild-type $(C)$, $f_{S}(2) 01672(D)$, and $f_{S}(3) 01295(F)$ nurse cells were stained with DAPI to reveal nurse cell chromocenters. Note the increased size of brightly stained chromocenters $(\mathrm{cc})$ in the mutants (cf. D,F with C). $f_{S}(2) 01672$ nurse cell nuclei also appear to be retarded in their morphological development (cf. B,S4 with E, arrowhead). Bar, $10 \mu \mathrm{m}$.

the developing germ-line cyst also provides the opportunity to examine the relationship between cell-cycle regulation and cell fate determination. The cell cycles of the future oocyte and nurse cells constitute one of their most immediate and striking differences. All 16 cyst cells enter a long $\mathrm{S}$ phase, characteristic of meiosis in numerous organisms. Both four-ring canal cells develop long synaptonemal complexes, while several other cells show similar but reduced structures (Carpenter 1975). However, these meiotic manifestations are maintained only in the pro-oocyte; they disappear in the future nurse cells. It remains unclear to what extent these distinct cell cycles represent a cause or effect of oocyte/nurse cell fate determination.

To identify genes that are important in regulating the nurse cell cycle, we screened for mutations that alter the under-representation of satellite DNAs in polyploid nurse cells. We identified a mutation that greatly increases the propagation of nurse cell heterochromatin, and showed that it represented a viable allele of the cyclin E gene. Our findings directly implicate cell-cycle programming via cyclin $\mathrm{E}$ in differential sequence replication during polyploidization and nurse cell/oocyte fate determination. 


\section{Results}

Identification of female sterile mutations with enlarged nurse cell chromocenters

Nurse cell chromosomes undergo developmental changes in nuclear structure during the 10-12 endocycles of oogenesis (for review, see King 1970). Initially, the homologous chromatids associate tightly to form small polytene chromosomes. During endocycles 4-5 /stage 4-5), the homolog pairing, banding, and shape of the chromosomes change, leading to nuclei with five large, diffuse oval-shaped chromatin blobs (Fig. 1B). By cycle 7 , DNA is distributed more evenly throughout nurse cell nuclei except in the vicinity of the large distinctive nucleoli. During most of this period, staining with the fluorescent DNA dye DAPI reveals one or a few small intensely labeled "chromocenters" (Fig. 1C), regions that represent dense aggregates of DNA rich in pericentric satellite sequences (Hochstrasser and Sedat 1987; L. Keyes and A. Spradling, unpubl.).

We reasoned that mutations in the process of DNA under-representation might alter the size and/or appearance of the nurse cell chromocenters. Consequently, we screened a collection of female sterile lines (Karpen and Spradling 1992) for changes in nurse cell chromosome structure. One mutation, fs(2)01672, contained nurse cell chromocenters that were increased dramatically in both size and intensity (Fig. 1D), suggesting that the mutant nuclei contained more heterochromatic sequences than wild type. The "5-blob" nuclear stage persisted in a fraction of $f_{S}(2) 01672$ nurse cells beyond endocycles 4-5, indicating that another effect of the mutation was to retard the normal process of chromatin changes (Fig. 1E). In addition, $30 \%$ of $f_{S}(2) 01672$ egg chambers contained only 8 instead of 16 cells: 7 nurse cells and a single oocyte.

A second mutation, $f_{S}(3) 01295$, also increased the size of nurse cell chromocenters (Fig. 1F). We mapped this insertion to cytogenetic position $88 \mathrm{D}$ and showed that it was allelic to $m s(3) 88 D$ (Berg and Spradling 1991), a hotspot for $P$-element insertion also known as effete (Castrillon et al. 1993). The effects of $f_{S}(3) 01295$ on nurse cell development will be presented elsewhere.

\section{fs(2)01672 nurse cells have increased DNA content}

If the $f_{S}(2) 01672$ mutant affected DNA representation, then the mutant nurse cells might contain extra heterochromatic sequences and a greater overall DNA content. To look for changes in total DNA content we developed a procedure for analyzing the DNA content of Drosophila ovarian nuclei using flow cytometry (see Materials and Methods). Nuclei were isolated from wild type and $f s$ (2)01672 ovaries, stained with DAPI (or propidium iodide), and sorted under conditions where DAPI fluorescence values ranging between the Drosophila haploid C value and $1000 \mathrm{C}$ are recorded linearly (Fig. 2). Follicle cells, which form an epithelial layer around most germline cysts, greatly outnumber nurse cells within the ovary (see Fig. 1B). Consequently, four large peaks corre-
A

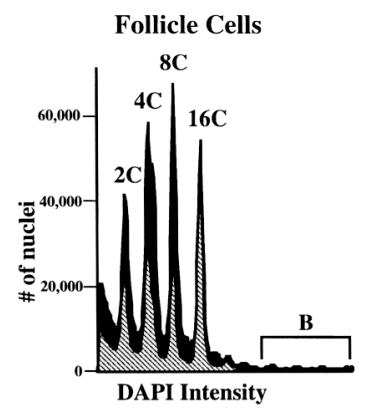

B

Nurse Cells

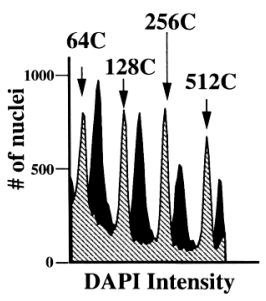

Figure 2. $f_{S}(2) 01672$ increases nurse cell DNA content. (A) Superimposed flow cytometry (FACS) profiles of DAPI fluorescence of ovarian nuclei from wild type (hatched) and fs(2)01672 (solid). The numbers over the peaks correspond to the copy number ( $\mathrm{C}$ value) of euchromatic sequences. Peaks in the range of $2 \mathrm{C}-16 \mathrm{C}$ are almost entirely due to follicle cells, while peaks above $32 \mathrm{C}$ are due almost entirely to nurse cells. The wild-type values on the $y$-axis were all multiplied by 0.6 to make it easier to visualize the peaks when plotted on the same graph. $(B)$ The region of the profiles in $A$ corresponding to nurse cell peaks greater than $32 \mathrm{C}$ (indicated by a bracket) is presented at a different scale.

sponding to $2 \mathrm{C}$ mitotic through $16 \mathrm{C}$ polyploid follicle cells are prominent (Fig. 2A). No differences in the relative amount of DAPI fluorescence were seen between wild-type and mutant follicle cell nuclei of any ploidy class.

Although nurse cell nuclei with low ploidy values are obscured by the follicle cell nuclei in mature ovaries, peaks corresponding to nurse cells in endocycles 6-10 are readily observed when the sorting profiles are examined in the $64 \mathrm{c}$ to $1000 \mathrm{c}$ range (Fig. 2B). Consistent with their expanded chromocenters, $f_{s}(2) 01672$ nurse cells are dramatically shifted to higher DNA values relative to wild type. This shift can be observed in mutant nurse cells as early as the second endomitotic cycle in ovaries from young females that lack egg chambers with highly polyploid follicle cells (data not shown). Eight independent flow cytometry runs on separate preparations of nuclei, each recording more than 1 million nuclei, showed that $f_{s}(2) 01672$ nurse cells had relative DNA contents of $123 \% \pm 4.0(64 \mathrm{c}), 121 \% \pm 3.2(128 \mathrm{c})$, and $117 \% \pm 5.9$ (256c) of wild-type controls. None of the nurse cell peaks from heterozygous $f_{S}(2) 01672 /+$ females differed significantly from wild type, indicating the effect on the DAPI fluorescence phenotype is recessive (data not shown). These data suggest that the $f(2) 01672$ nurse cell nuclei contain more DNA than wild-type nurse cells that have undergone the same number of endoreplicative cycles.

\section{fs(2)01672 nurse cells have increased amounts of two heterochromatic sequences}

The increased DAPI fluorescence of $f_{S}(2) 01672$ nuclei supported the idea that these nuclei contain a substantially increased amount of DNA, much or all of which 
may be satellite DNAs that contribute to the expanded chromocenter. However, DAPI fluorescence could in principle be affected by nuclear size, shape, and altered chromatin organization, as well as by DNA content. Therefore, we examined directly whether the representation of two heterochromatic sequences, 1.688 satellite and rDNA, was increased in fs(2)01672 nurse cells. Single peaks, representing individual ploidy classes, were collected from wild-type and mutant ovaries using a fluorescence-activated cell sorter. DNA was extracted from the samples and duplicate slot blots were hybridized with either a euchromatic probe or a heterochromatic probe. The ratio of the signal from the heterochromatic probe to the signal from the euchromatic probe was determined for all classes of nuclei. Mitotically active diploid disc DNA, considered to be $100 \%$ represented for all heterochromatic sequences, was used for normalization.

As predicted, the copy numbers per haploid genome of the two heterochromatic sequences were increased significantly in $f_{s(2) 01672}$ nurse cells (Fig. 3). The 1.688 satellite sequence, a 359-bp repeat present in X-chromosome centric heterochromatin that accounts for about $4 \%$ of total DNA, was 2.1 (128c) and 4.1 (256c) times more abundant than in wild type (Fig. 3A). Drosophila rDNA makes up about $2.5 \%$ of the diploid genome and is located in females within the $X$ chromosome centric het-

\section{$\mathbf{A}$}
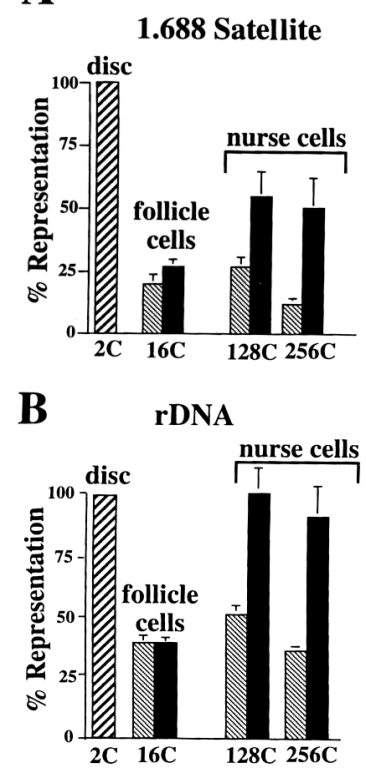

Figure 3. $f_{S}(2) 01672$ nurse cells contain an increased copy number of two heterochromatic sequences. The relative copy numbers of 1.688 satellite sequences $(A)$ and rDNA sequences $(B)$ in wild-type (hatched) vs. $f(2) 01672$ (solid) polyploid nurse and follicle cells were determined by hybridization to DNA purified from flow-sorted nuclei of the indicated ploidy classes that had been immobilized on slot-blots. Data were normalized using wild-type disc DNA. Each experiment was performed twice using euchromatic DNA from two different regions of the genome, $70 \mathrm{~A}$ and $23 \mathrm{C}(n=4)$. Standard deviations are shown by bars. erochromatin. Approximately $50-60 \%$ of rDNA repeats on the $X$ chromosome are disrupted by a $\mathbf{R} 1$ or $\mathbf{R} 2$ retrotransposon (see Endow and Glover 1979). These interrupted nonfunctional rDNA repeats become under-represented during polyploidization (Endow and Glover 1979; Beckingham and Thompson 1982). In the two classes of wild-type nurse cells examined, rDNA is present at only $40-50 \%$ of euchromatic representation levels. This reduction in copy number was almost completely blocked in $f_{s}(2) 01672$ nurse cells (Fig. 3B). In other words, in $f_{s}(2) 01672$ nurse cells the rDNA is present at the same copy number per haploid genome as in mitotic cells. In contrast, the $f_{s}(2) 01672$ mutation had no effect on the representation of 1.688 satellite or $\mathrm{rDNA}$ in $16 \mathrm{c}$ endopolyploid follicle cells (Fig. 3A,B). These data confirm that the actual DNA content of $f_{s}(2) 01672$ nurse cells was greater than wild type due to the increased propagation of under-represented heterochromatic DNAs.

These results argue strongly that $f_{S}(2) 01672$ nurse cells contain a significantly increased content of heterochromatic DNAs that are normally under-represented during polyploidization. The major satellite DNAs together constitute about $22 \%$ of the genome in mitotic cells (Lohe and Brutlag 1986). Were they generally affected in the same manner as that of the 1.688 satellite (i.e., returned from $12.5 \%$ to $\sim 50 \%$ of full representation), and considering the observed changes in rDNA (i.e., increased from $50 \%$ to $100 \%$ of full representation), then the DNA content of the nurse cells would be expected to increase to a value $\sim 13 \%$ greater than in a wild-type nurse cell of equivalent ploidy, close to the observed $17-23 \%$ increase in DAPI fluorescence.

\section{$\mathrm{fs}(2) 01672$ is a novel female sterile allele of cyclin $E$}

The $f_{s}(2) 01672 P$ element was cytogenetically mapped at position $35 \mathrm{D}$ by in situ hybridization to salivary gland polytene chromosomes (data not shown). The female sterility was uncovered by a deletion for the region, $D f(2 L) r 10$, and excision of the $f_{s}(2) 01672 P$ element restored female fertility and reverted the nurse cell chromocenter phenotype. Thus, the insertion is responsible for the observed defects in this strain. The Drosophila cyclin E gene DmcycE (cycE) is located within the same polytene division as $f_{S}(2) 01672$ (Richardson et al. 1993). Four independent lethal alleles of $c y c E$ were tested for allelism and all failed to complement $f_{s}(2) 01672$ for female fertility. The phenotype of $c y c E^{\text {lethal } / f s(2) 01672}$ trans-heterozygotes is more severe than the $f_{s}(2) 01672$ homozygotes. cycE $E^{\text {lethal }} / f_{S}(2) 01672$ polyploid nurse cells have abnormally large chromocenters, but egg chambers rarely progress beyond stage 5 or 6 (data not shown). Thus, $f_{s}(2) 01672$ behaves genetically as a partial loss-offunction mutation in $c y c E$.

Genomic DNA flanking the $f_{s}(2) 01672 P$ element was recovered by plasmid rescue. Analysis of the recovered DNA using a $c y c E$ type II cDNA as probe (Richardson et al. 1993) localized the $f_{s}(2) 01672$ insertion to an $8-\mathrm{kb}$ $E c o$ RI fragment in the first intron of the $c y c E$ type II 
maternal transcript (Fig. 4A). Several $P$ element-induced lethal alleles of $c y c E$ recovered from the same genetic screen map within this same intron (Knoblich et al. 1994).

\section{The $\mathrm{cycE}^{01672}$ mutation alters CycE oscillation during nurse cell development}

To analyze the effects of $c y c E^{01672}$ on cyclin E protein, ovaries were dissected from wild-type and $c y c E^{01672} \mathrm{fe}$ males, fixed and stained with a monoclonal antibody against Drosophila CycE (Richardson et al. 1995). Cyclin E levels have been shown to oscillate during the cell cycle in mammalian tissue culture cells (Dulic et al. 1992; Koff et al. 1992). In wild-type flies, CycE was expressed at varying levels, suggesting cycling, in both nurse and follicle cells (Fig. 4C,D). Within individual egg chambers, nurse cell nuclei with high, intermediate, and low or undetectable levels of cycE protein were observed. Interestingly, CycE protein staining was always high in

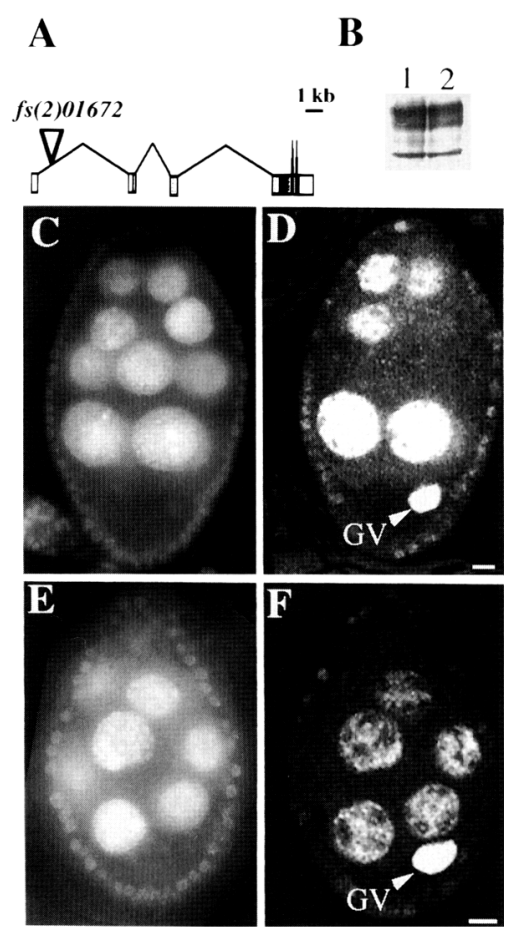

Figure 4. Periodic CycE expression is altered in $c y c E^{01672} \mathrm{egg}$ chambers. $(A)$ Structure of $c y c E$ type II transcription unit (Richardson et al. 1993) showing the location of the $f_{S}(2) 01672$ insertion. (B) Western blot comparing the amount of CycE in wild type (1) and $f s(2) 01672$ (2) ovaries. Equivalent amounts of protein were present based on staining of the transferred blot with ponceau S. $(C-F)$ Stage 8 egg chambers are compared from wild-type $(C, D)$ and $f_{S}(2) 01672(E, F)$ following staining with DAPI $(C, E)$ and with a monoclonal antibody (Richardson et al. $1995)$ against CycE $(D, F)$. CycE levels in wild-type nurse cell nuclei vary extensively, and include both intensely stained and unstained nuclei. In $c y c E^{01672}$ nurse cells, the nuclei with the highest levels of staining are not found, but a larger fraction contain detectable CycE. Bar, $10 \mu \mathrm{m}$. the "germinal vesicle" $(\mathrm{GV})$, the specialized nucleus of the oocyte.

CycE protein was still readily detected in $c y c E^{01672}$ nurse cells (Fig. 4E,F), but two differences were apparent. First, the highest levels of staining characteristic of 20$30 \%$ of wild-type cells were very rarely observed. Second, fewer nurse cells contained very low or undetectable CycE levels. High levels of protein were still seen in the germinal vesicle. Thus, the dramatic oscillations in cycE levels characteristic of wild-type nurse cells were dampened as a result of the mutation. No differences in the oscillation of CycE protein in follicle cells were observed between wild-type and mutant egg chambers, although the overall levels appeared to be lower in mutant ovaries. Similar analysis using antibodies specific for cyclin A and cyclin B showed that these proteins were undetectable in wild type and $c y c E^{01672}$ nurse cells /data not shown).

Western blot analysis was carried out on wild-type and $c y c E^{01672}$ ovaries to investigate further the changes caused by the mutation. Surprisingly, no significant decrease in CycE levels was observed (Fig. 4B). In addition, the size distribution of $\mathrm{CycE}$ protein isoforms was not altered. The fact that reductions in CycE levels were not apparent in whole ovary Western blots is probably due to several factors. First, the reduction in strong nurse cell expression may have been partially compensated by the greater fraction of cells expressing at least some CycE. Moreover, the majority of CycE protein may have derived from outside nurse cell nuclei: from nurse cell cytoplasm, the follicle cells, and especially from the oocyte nucleus. Unlike the cycling that is observed in nurse and follicle cell nuclei, CycE remained high in the germinal vesicle (GV) and its intensity increased as egg chambers develop in both wild-type and the $c y c E^{01672}$ ovaries (Fig. $4 \mathrm{D}, \mathrm{F})$. It is not known whether the CycE present in the GV is actively complexed with a cyclin-dependent kinase (cdk) or whether the GV simply represents a site of CycE storage.

\section{Late replication is restored in $\mathrm{cycE}^{01672}$ nurse cells}

Higher eukaryotic genomes are replicated in specific temporal patterns. Euchromatic sequences usually replicate in early to mid-S phase, whereas sequences within heterochromatin, such as satellite DNA and rDNA, replicate in late $S$ phase. The temporal pattern of DNA replication can be visualized by briefly labeling sites of ongoing DNA replication with the thymidine analog BrdU. Cells in early to mid-S phase incorporate BrdU throughout the entire nucleus, whereas cells in late $S$ phase are distinctive because BrdU labeling is confined to chromocenters, the principle sites of aggregated heterochromatin.

To examine whether alterations in the temporal control of $\mathrm{S}$ phase might be responsible for the increased copy number of heterochromatic sequences in $c y c E^{01672}$ nurse cells, we used BrdU incorporation to monitor DNA replication. When wild-type ovaries were labeled with BrdU for $1 \mathrm{hr}$, both early and late replication pat- 
terns were apparent in the mitotically active follicle cells (Fig. 5A). However, following entry into the endocycle, late replication patterns were never observed (Fig. $5 B$ ), even during the first endocycle. A very similar situation was observed in the germ-line cells. Germ-line stem cells and mitotically active cystocytes showed characteristic early and late S-phase patterns (Fig. 5C). However, as soon as the first nurse cell endocycle had been initiated, nearly all nurse cells showed only early patterns of incorporation (Fig. 5D). Less than 2\% (9/475) of wild-type nurse cells were ambiguous or appeared to have late incorporation. Since wild-type nurse cells, unlike follicle cells, do replicate satellite DNA to a low level, this may explain the presence of a few nuclei with late replication patterns.

The $c y c E^{01672}$ mutation had a striking effect on the temporal organization of $S$ phase in nurse cells. Approximately $15 \%(67 / 450)$ of the $c y c E^{01672}$ nurse cells that
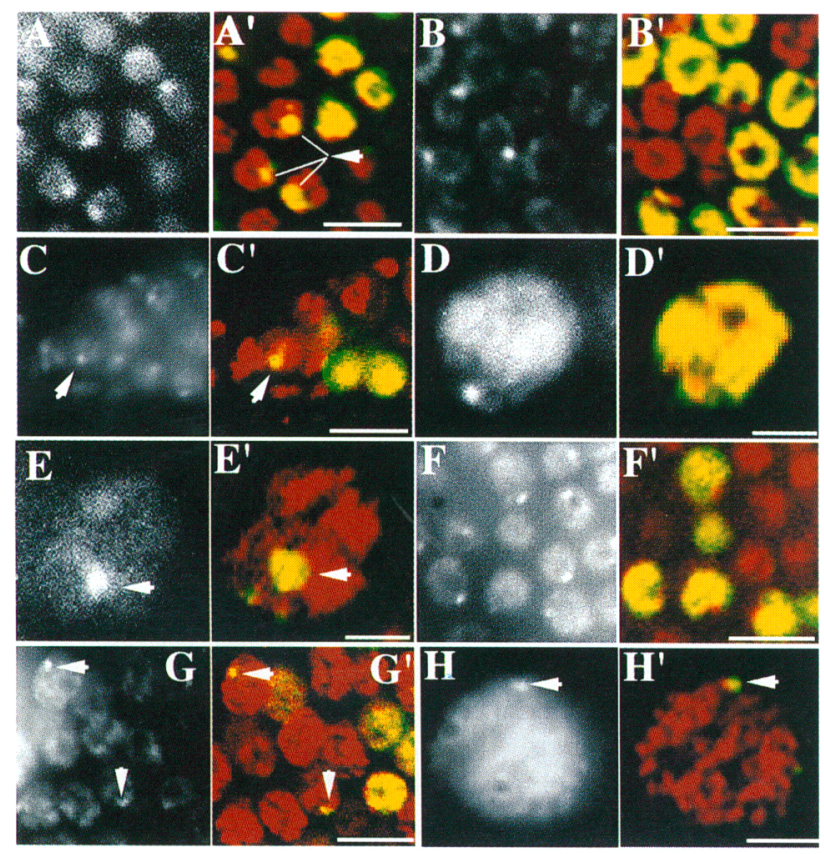

Figure 5. Late replicating heterochromatin is restored to nurse cells but not follicle cells by the $c y c E^{01672}$ mutation. Each panel shows DAPI staining $(A-H)$ on the left and the corresponding BrdU incorporation patterns $\left(A^{\prime}-H^{\prime}\right)$ on the right (green, BrdU; red, propidium iodide $).\left(A, A^{\prime}\right\rangle$ Wild-type mitotic follicle cells from stage $5 .\left(B, B^{\prime}\right)$ Wild-type endomitotic follicle cells from stage 10B. Note that mitotic but not endomitotic follicle cells have late DNA replication patterns. $\left|C, C^{\prime}\right|$ Wild-type germ-line stem cell (arrow); also note BrdU incorporation into two cells of a developing cyst. $\left(D, D^{\prime}\right)$ Wild-type stage 7 endomitotic nurse cell. $\left(E, E^{\prime}\right) c y c E^{01672}$ polyploid nurse cell from a stage 5 egg chamber with a late replication pattern. $\left(F, F^{\prime}\right)$ Follicle cells from a stage $7 \mathrm{CycE^{01672 }}$ chamber showing the absence of late replication patterns. In ovaries from heat-shocked females carrying the hs-cycE transgene, late patterns of DNA replication were observed in both endomitotic follicle cells $\left(G, G^{\prime}\right)$ and endomitotic nurse cells $\left(H, H^{\prime}\right)$. Bar, $10 \mu \mathrm{m}$ in all panels except $\left(E, E^{\prime}\right)$, where it represents $5 \mu \mathrm{m}$. incorporated the label appeared to be in late S-phase (Fig. $5 \mathrm{E})$. Under the same conditions, late S-phase endomitotic follicle cells were never observed (Fig. 5F). These data demonstrate that the $c y c E^{01672}$ mutation restores late DNA replication to endomitotic nurse cells, but not to follicle cells. It is likely that the recovery of late S-phase replication is responsible for the increased copy number of heterochromatic sequences observed in $c y c E^{01672}$ polyploid nurse cells.

\section{Ectopic expression of cycE produces late DNA replication patterns in polyploid nuclei}

In $c y c E^{01672}$ polyploid nurse cells $\mathrm{CycE}$ is present throughout a longer proportion of the cell cycle. To determine whether this alteration in the kinetics of cycE oscillation is responsible for the addition of late replication to the nurse cell endocycle, we ectopically expressed high levels of CycE in the ovary using an hs-cycE transgene (Knoblich et al. 1994). If the alteration in endomitotic $S$ phase is due to the decreased ability of the mutant to down-regulate CycE levels, then providing high levels of CycE should phenocopy the $c y c E^{01672} \mathrm{mu}-$ tation in nurse cells. Consistent with this prediction, when hs-cycE females were heat-shocked and their ovaries labeled with BrdU, late DNA replication patterns were observed in $>10 \%$ of incorporating nuclei in both polyploid nurse and follicle cells (Fig. 5G,H). Thus, high levels of CycE restore late replication to the polyploid cycle. Mis-expressing cyclin A using an hs-cycA transgene (Knoblich and Lehner 1993) also induced late replication, generating patterns of BrdU incorporation very similar to those in Fig. 5G,H (data not shown). Thus, altering the kinetics of CycE oscillations changes the temporal profile of endomitotic $S$ phase.

\section{cycE $^{01672}$ cysts frequently contain multiple ooctyes}

$c y c E^{01672}$ females exhibited one additional striking defect. In $c y c E^{01672}$ egg chambers, frequently two instead of just one of the 16 cyst cells differentiated as oocytes. Since the level of CycE protein in the GV is high, and the oocyte contains only a $4 \mathrm{c}$ complement of DNA, double staining with anti-CycE and DAPI differentially labeled these nuclei (Fig. 6A). In $c y c E^{01672}$ ovaries $30-40 \%$ of egg chambers contained germ-line cysts with two GVs (Fig. $6 \mathrm{~B}$ ) and $\sim 5 \%$ of egg chambers contained three such nuclei (Fig. 6C). This change in cell fate occurred very early after completion of the 16 cell cysts. By stage 3 of oogenesis, the oocyte nucleus condenses into a transcriptionally quiescent karyosome that can be distinguished morphologically from the developing nurse cells. Egg chambers as young as stage 3 from $c y c E^{01672}$ females frequently contained two nuclei that had condensed and failed to polyploidize.

Egg chambers that contained two GVs invariably contained only 14 nurse cells, demonstrating that the extra oocyte arose by transformation of a cell normally fated to differentiate as a nurse cell. The extra oocyte nucleus was smaller, always located in a small cell that lacked 

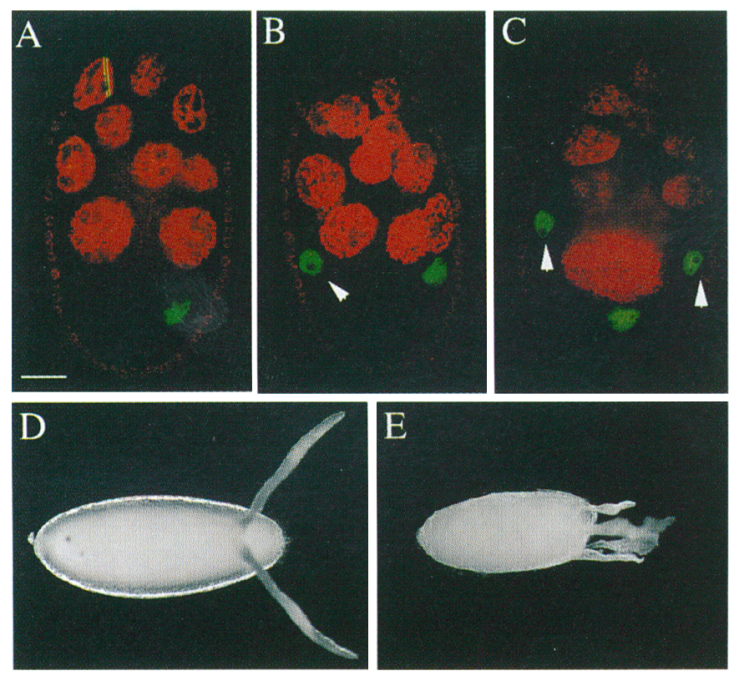

Figure 6. $c y c E^{01672}$ alters cell fate and pattern in developing egg chambers. Egg chambers stained with propidium di-iodide (red) and anticyclin $\mathrm{E}$ (green) are shown from the wild type $(A)$ and $c y c E^{01672}(B, C)$. Normally $(A)$, only one of the 16-cyst cell nuclei differentiates as an oocyte nucleus $(\mathrm{GV})$, which stains green due to its relatively low (4C) DNA content. In contrast, $30-40 \%$ of $c y c E^{01672}$ chambers had two germinal vesicles $(B)$ and rarely three of the 16 nuclei differentiated as GVs $(C)$. The extra GVs (arrowheads) were always located adjacent to the oocyte, and appeared to be retarded in development, as indicated by the morphological appearance of the endobody /clear circular areas in extra GVs). Mature eggs produced by $c y c E^{01672}$ females $(E)$ sometimes have more dorsal appendages than the two characteristic of wild type $(D)$, indicating that both the normal and extra GVs are active in signaling the overlying follicle cells. Bar, $25 \mu \mathrm{m}$.

yolk or other signs of cytoplasmic oocyte differentiation, and lay adjacent to the true oocyte at the posterior of the egg chamber. By staining with rhodamine phalloidin to label the actin in ring canals, we confirmed that the extra oocyte in two-oocyte cysts contains four ring canals (data not shown). Several aspects of nuclear differentiation differed between the normal and extra oocyte nucleus. The timing of events in the second GV appeared to be slightly retarded. This was suggested by the small size of the extra GV and the retention of an intact endobody until late in oogenesis (Fig. 6B,C). In addition, the extra oocyte nucleus frequently was observed plugging the ring canal joining the true oocyte in stage 10 egg chambers, suggesting that it had been drawn into the canal as occurs with nurse cell nuclei in mutants that block actin bundle formation (data not shown).

To investigate whether the extra oocyte nucleus was capable of functioning in egg chamber patterning, we examined the morphology of eggshells produced by those $c y c E^{01672}$ egg chambers that complete development. The germinal vesicle is known to be crucial for patterning the follicle cells on the dorsal side of the egg chamber (for review, see Anderson 1995). The follicle cells that overlie the GV produce a distinctly patterned dorsal egg shell and the dorsal appendages (Fig. 6D). One would predict that $c y c E^{01672}$ egg chambers that contain two GVs, and therefore two sources of dorsalizing activity, would produce egg shells with pattern defects. Consistent with this hypothesis, a fraction of mature $c y c E^{01672}$ eggs contain one to two additional dorsal appendages (Fig. 6E).

\section{Discussion}

Cyclin $E$ is an important regulator of nurse cell endocycles

Our experiments show that $\mathrm{CycE}$ is an important regulator of nurse cell endocycles. We observed $\mathrm{CycE}$, but not cyclin A or cyclin B, in endocycling nurse and follicle cells. Furthermore, a $c y c E$ mutation, $c y c E^{01672}$, disrupts nurse cell growth and perturbs the endocycle. Previously, cycE was shown to be the only known cyclin expressed in endocycling gut and Malphigian tubule cells in early embryos (Knoblich et al. 1994). Both removal and ectopic expression of CycE suggested that this protein was an important regulator of the endocycle in these cells (Sauer et al. 1995; Duronio and O'Farrell 1995 ). Our observations support the suggestion that $\mathrm{CycE}$ is a primary regulator of endocycles in a wide variety of embryonic, larval, and adult cells.

There are several steps at which a CycE-mediated control is likely to act. First, CycE may be required to initiate $S$ phase and for ongoing DNA replication. Second, CycE may inhibit DNA re-replication. In a variety of other organisms cdk activity plays an important role in inhibiting DNA re-replication by preventing the premature conversion of spent replication complexes to the active prereplicative state during $S, M$, and $G_{2}$ (for review, see Heichman and Roberts 1994; Dahmann et al. 1995; Su et al. 1995). In the mitotic cycle, origins are reset during late mitosis when cyclin-cdk kinase activities are low. In endocycling cells, which bypass mitosis and fail to express mitotic cyclins or cdc2, a window of low cyclin-cdk activity may be achieved through the cyclic regulation of CycE expression (Knoblich et al. 1994; Duronio and O'Farrell 1995; Sauer et al. 1995). Thus, CycE levels alternately may need to be high to promote DNA replication and low to reset the endocycle and allow origins to prepare for a subsequent round of replication.

\section{The nurse cell endocycle truncates $S$ phase}

The genomes of higher eukaryotes are replicated in a temporally controlled manner within the $\mathrm{S}$ phase of mitotic cells. Heterochromatic chromosome regions rich in highly repetitive DNAs are almost invariably replicated late in S, after the rest of the genome has finished duplicating. As a result, distinctive late replication patterns are observed in a significant fraction of mitotic cells following brief periods of BrdU incorporation. In yeast, some replication origins, especially those located near telomeres, have been shown to initiate only late during $\mathrm{S}$ phase (for review, see Fangman and Brewer 1992). How 
late origins are controlled and whether specific cyclincdks or other cell-cycle regulators play a role will require further study. Moreover, very little is known about the temporal control of $S$ phase in endocycling cells.

Our results showed that the onset of endocycles correlates with the loss of a distinct late $S$ phase. Prior to beginning endocycles, mitotic Drosophila germ-line and follicle cells exhibit patterns of late DNA replication similar to those in other diploid cells (Fig. 5A,C). Late replication patterns disappear from follicle cells as soon as they enter the endomitotic cycle and are only rarely observed in endomitotic nurse cells (which do replicate a small amount of satellite DNA). These observations suggest a simple explanation for why satellite DNAs and other late replicating sequences become under-represented in nurse cells and many other endocycling cells. S phase may not proceed to completion during the endocycle, preventing or greatly reducing the replication of those sequences that reduplicate near the end of $S$.

The effects of $c y c E^{01672}$ on DNA replication strongly support the view that $S$ phase is truncated in endocycling cells. More than seven times as many $c y c E^{01672}$ nurse cells show late replication patterns compared with wild type. Concomitantly, these cells accumulate 15-20\% more DNA than wild-type nurse cells that have undergone the same number of endoreplicative cycles; most or all of the extra DNA can be accounted for by the increased satellite DNA content. These observations show that there is nothing inherently incompatible between endocycles and the replication of satellite DNA late in the $\mathrm{S}$ phase. The mutation may restore a missing signal or simply prolong $\mathrm{S}$ phase, allowing the same temporal program of DNA replication to be completed as in mitotic cells.

\section{A model for CycE regulation of the endocycle}

We considered two ways to explain why a hypomorphic mutation in $c y c E$ restores a late $S$ phase. First, a specific regulator may be required for the onset of late DNA replication. In mammalian cells cyclin A plays a critical role in $\mathrm{S}$ phase at a slightly later time than cyclin $\mathrm{E}$ (Guadagno et al. 1993). If cycA were specifically required for late $S$, its absence in nurse cells and other endocycling cells would explain the failure of satellite DNA to replicate. How then could a $c y c E$ mutation restore late S? Work from budding yeast has shown that cyclins can influence the expression of other cyclin family members (Amon et al. 1993). The altered cycE oscillations in $c y c E^{01672}$ nurse cells might increase cyclin A expression to levels sufficient to induce late DNA replication. To investigate this possibility, we looked for cyclin A and cyclin B expression in $c y c E^{01672}$ endomitotic nurse cells, but were unable to detect either protein. While these experiments do not support the model, neither do they rule out the possibility that a different regulator specifically controls late replication or address whether cyclin A plays an important role during late replication in the mitotic cycle.

Because we were unable to associate a specific regula- tor with the onset of late $\mathrm{S}$ phase, we favor a model for the nurse cell endocycle based on the control of $S$ phase length (Fig. 7). The model incorporates several features suggested by previous studies. First, the alternating $S$ and $G$ phases characteristic of the endocycle are postulated to be determined by periodically rising and falling levels of cyclin E (Duronio and O'Farrell 1995; Sauer et al. 1995). Second, CycE is assumed to negatively regulate its own production, as in embryonic endocycles (Knoblich et al. 1994; Duronio and O'Farrell 1995). Third, low levels of CycE are postulated to be needed to allow replication origins to be reset for firing (Su et al. 1995). Finally, a key ingredient of the model is the lack of any checkpoint control exerted by unreplicated DNA on the CycE oscillator. In mitotic cells, the completion of $\mathrm{S}$ phase is ensured because active replication forks inhibit mitosis through a cdc2-dependent mechanism (Heichman and Roberts 1994). Since endocycling cells lack cdc2 and its associated mitotic cyclins, it is not surprising that this checkpoint ceases to operate.

These factors provide the following picture of an endocycle (Fig. 7). At the start of a new cycle, negligible levels of CycE allow replication origins to be "reset" for firing and turn off a CycE-dependent down-regulation
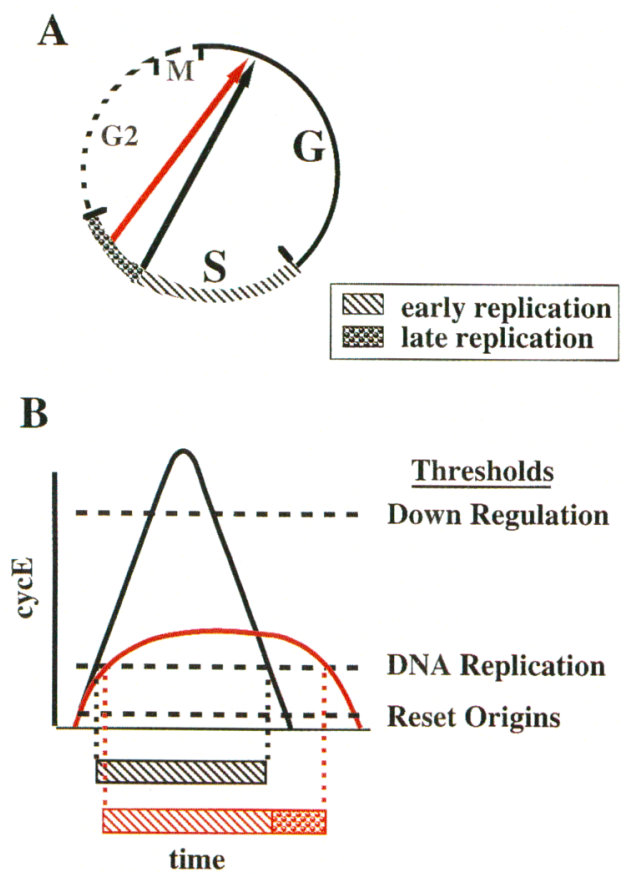

Figure 7. CycE oscillation controls polyploid S phase. $\{A \mid$ Proposed model for how a generic mitotic cell cycle is truncated in the wild type (black) and $c y c E^{01672}$ (red) polyploid nurse cells. (B) Graph showing how CycE oscillation is proposed to control the polyploid cell cycle. As levels of CycE rise at the start of a cycle, replication begins when a threshold concentration is reached ("DNA Replication"). Further increases in CycE concentration take place until down regulation is initiated at a second threshold ("Down Regulation"). Finally, the cycle is reset when CycE levels fall below a minimum value ("Reset Origins") that allows the cycle to start again. Colors as in $A$. 
system. As CycE concentrations rise, replication begins when a critical level is reached (Fig. 7B, "DNA Replication"). CycE levels continue to rise until a second threshold is attained (Fig. 7B, "Down Regulation") and induces the down-regulation machinery. Once $\mathrm{CycE}$ falls below a critical level, $\mathrm{S}$ phase ceases and the cycle repeats (Fig. 7B, "Reset Origins"). Consequently, the extent of replication will be determined primarily by the length of $S$ phase and an intrinsic, temporal program of DNA replication similar to that in mitotic cells. A relatively short CycE cycle would prevent genomic replication from being completed, while a longer cycle would allow most or all of the genome to duplicate.

According to this model, the $c y c E^{01672}$ mutation exerts its effects on DNA representation (Fig. 7A) by altering the kinetics of CycE oscillation (Fig. 7B). The cycle is reset and accumulation begins as in wild-type cells, and the relatively low levels needed to initiate the $S$ phase are quickly attained. However, the reduced efficiency of CycE production from the mutated gene prevents the relatively high threshold necessary for down-regulation from ever being reached. Consequently, CycE levels sufficient to support DNA replication persist for longer than in wild-type cells, leading to a longer $S$ phase. Eventually, CycE degradation does occur, either through an alternative pathway or following delayed induction of the normal down-regulation mechanisms. The extended $S$ phase allows replication of a much larger fraction of satellite DNAs, rDNAs, and other late replicating sequences to be completed than in the wild type. Cells replicating such DNA exhibit localized BrdU incorporation characteristic of late mitotic $S$ phases. This simple model explains all our observations on $c y c E^{01672}$ mutant nurse cells, including the higher fraction of mutant nurse cells that contain $\mathrm{CycE}$, the dearth of cells with high CycE levels, and the appearance of late replication patterns of BrdU incorporation.

This model also explains the effect of overexpressing CycE from a heat shock promoter. Greatly increased CycE production probably lengthens the time required to degrade CycE to levels necessary for resetting, even in the presence of activated down-regulation. During this extended period, sufficient $\mathrm{CycE}$ remains to allow continued DNA replication, leading to an extension of $S$ phase and the completion of much or all of late $S$ phase. Similar effects would be expected to result from cyclin A over-expression, as observed.

Additional mutations altering the kinetics of $\mathrm{CycE} c y$ cling or the rate of $S$ phase progression are predicted by the model to influence heterochromatic sequence representation in polyploid nuclei. One class of such mutants would be those that effect CycE transcription. In addition, CycE contains PEST motifs (Richardson et al. 1993) and is likely to be degraded via the ubiquitin pathway. Mutations in ubiquitin pathway genes that carry out CycE degradation would be expected to increase the persistence of CycE protein and lengthen the nurse cell $\mathrm{S}$ phase, leading to increased heterochromatin content. Consistent with this proposal, we found that $f_{s}(3) 01295$, an allele of effete, increases dramatically the size of nurse cell chromocenters (Fig. 1F). effete recently has been shown to encode the Ubc-D1 ubiquitin conjugating enzyme (R. Rawson and S. Wasserman, pers. comm.).

\section{Differential replication can explain many previous observations on polytene endocycles}

Patterns of ${ }^{3} \mathrm{H}$-thymidine incorporation into polytene salivary gland chromosomes previously have been observed to fall into distinctive temporal classes (for review, see Rudkin 1972). Late in the S phase of mature third instar larval glands, incorporation is limited to a few bands and the polytene chromocenter. These late replicating sequences are unlikely to be satellite DNAs, which do not replicate during salivary gland polytenization. Our results suggest that sequences replicating late in a normal polytene $S$ phase correspond to those replicating just prior to late $S$ in a mitotic cycle.

Endocycling cells show tissue-specific differences in the extent to which particular heterochromatic sequences replicate. For example, all the satellite DNAs replicate to some extent in Drosophila nurse cells, while little or no increase in satellite DNA content occurs in follicle cells or salivary gland cells (reviewed in Spradling and Orr-Weaver 1987; Fig. 3). Our results suggest that two interacting factors will determine whether a chromosome region becomes under-represented in a given cell. First, cells may truncate the $S$ phase at different points, due to differences in the kinetics of CycE oscillation or the rate of S-phase progression. A second factor determining replication during the endocycle would be the time of replication of a sequence during $\mathrm{S}$ phase.

Changes in one or both of these factors are likely to account for the tissue-specific differences noted previously. Follicle cells probably complete a smaller fraction of $S$ phase than nurse cells as a result of differences in the parameters controlling $\mathrm{CycE}$ oscillation. These differences could explain why no increase in heterochromatic sequences was observed in $c y c E^{01672}$ follicle cells, despite the fact that CycE levels appeared to be reduced. Endopolyploid cells such as the Bombyx mori silk gland where satellite DNAs are fully replicated (Gage 1974) may either replicate these sequences early in $S$ phase or undergo endocycles that do not truncate the $S$ phase. Differences in the relative amounts of satellite DNAs between polyploid tissues (Endow and Gall 1975) would reflect tissue-specific differences in the degree to which late $S$ phase had been completed. Pericentromeric domains that replicate fully (Zhang and Spradling 1995) may contain replication origins that are activated in early to mid-S phase. There may be some stochastic variation in the period of CycE oscillation between different endocycles and between cells within a tissue. This could account for cell-to-cell heterogeneity in the content of specific $r D N A$ repeats within individual polyploid nurse cells (Belikoff and Beckingham 1985).

Our results may also provide insight into the interesting differences in chromosome structure between different polyploid and polytene cells. In particular, some somatic cells fail to replicate not only centric heterochro- 
matin, but probably even late-replicating euchromatin. There is strong cytological evidence from studies of salivary gland polytene chromosomes to support this prediction. The ploidy of salivary gland polytene chromosomes varies by several-fold along their length, and is 10to 20 -fold less in a few scattered regions known as "constrictions" (Spierer and Spierer 1984). Constrictions are known to replicate late in the S phase of the salivary gland endocycle (Rudkin 1972; Zhimulev et al. 1982). Indeed, the tight alignment of individual DNA strands characteristic of polytene chromosomes might itself be facilitated by the failure to complete the euchromatic portion of $\mathrm{S}$ phase. Our experiments predict that some replication forks are likely to remain when replication ceases at the end of the endocycle. If such forks were to accumulate through successive rounds of replication, they would give rise to "onion skin" structures such as those predicted previously (see Hammond and Laird 1985). So far such forks have not been found (Glaser et al. 1992). However, the fate of these forks may provide insight into the chromosome structure of endocycling cells.

\section{Nurse cell/oocyte fates may be controlled by cell-cycle programming}

The mechanism of oocyte determination has been the subject of considerable interest. The differential transport of specific mRNAs into the future oocyte in early 16-cell cysts is critically important. However, which transported components actually act as oocyte determinants and how they program the oocyte fate remain unclear. Our observations suggest that changes in cell-cycle regulation are closely tied to the nurse cell/oocyte fate decision. A substantial fraction of the cysts produced by cycE $E^{01672}$ mothers contained 16-cell cysts in which two or even three of the nuclei displayed characteristics of the oocyte nuclei. This effect was particularly significant, since previously described mutations inhibit oocyte differentiation and frequently produce cysts containing only nurse cells.

There are two likely sites for the action of CycE on oocyte determination. The pro-oocyte initially enters the meiotic pathway immediately following the completion of the cystocyte divisions. Consequently, the exact nature of the cystocyte cell cycles may influence the susceptibility of cystocytes to enter meiosis. Perturbations in CycE production might alter the kinetics or final cell-cycle state of cystocytes in a manner that promotes entry into meiosis. Several previous observations are consistent with the proposed connection between cystocyte divisions and oocyte determination. Mutations in otu (Storto and King 1989), hts (Yue and Spradling 1992), encore (Hawkins et al. 1996), and stonewall (Clark and McKearin 1996) all affect both cyst formation and oocyte differentiation. A close connection between these processes is further suggested by our observation that $30 \%$ of the cysts produced by $c y c E^{01672}$ females contain only eight cells. Unlike the 16-cell cysts, these cysts always differentiated a single oocyte.
A second possibility is that the determinants transported from the future nurse cells after cyst completion directly affect cell-cycle programming in the future oocyte. The molecular switch controlling entry into meiosis remains poorly known in multicellular eukaryotes, but it is plausible that cell-cycle proteins acting near the $G_{1}-S$ transition are involved. Changes in $\mathrm{CycE}$ levels caused by the $c y c E^{01672}$ mutation might increase the sensitivity of cystocytes to these determinants. This would explain why the ectopic oocyte always contained four ring canals, since the nurse cell with four ring canals is likely to experience transiently the highest level of determinants while they are in transit to the oocyte proper. Further study of the role of $c y c E$ during Drosophila development undoubtedly will provide significant new insight into the role of the cell cycle in diverse developmental mechanisms.

\section{Methods}

Drosophila strains and cultures

Flies were grown on standard corn/meal media at $22^{\circ} \mathrm{C}$ in bottles or vials as appropriate. The $c y c E^{01672}, c y c E^{05206}$, and ${ } y c E^{05277}$ mutations were recovered from a singe $P$-element mutagenesis (Karpen and Spradling 1992). The cycE mutations $\left.1(2) 35 D d^{p 28}, I(2) 35 D d^{p 41}, 1 / 2\right) 35 D d^{T E 116}$, and $D f(2 L)_{1} 10$ isee Fly. base 1994) were provided by J. Roote and M. Ashburner (University of Cambridge, UK). The hs-cycE stock was provided by Larry Zipursky (University of California, Los Angeles) and is described in Knoblich et al. (1994). The hs-cycA stock was provided by Christian Lehner (Knoblich and Lehner 1993).

\section{Nuclear isolation and flow cytometry}

Whole ovaries were dissected in Drosophila Ringers (Ephruzzi Beadle Ringer: $130 \mathrm{~mm} \mathrm{NaCl}, 5 \mathrm{mM} \mathrm{KCl}, 2 \mathrm{~mm} \mathrm{CaCl}_{2}$, and 10 $\mathrm{mM} \mathrm{HEPES}$ at $\mathrm{pH} 6.9$ ) and digested in EBR $5 \mathrm{mg} / \mathrm{ml}$ collagenase for $15 \mathrm{~min}$. Ovaries were rinsed to remove residual collagenase and placed in nuclear isolation buffer $(15 \mathrm{mM}$ Tris- $\mathrm{HCl}$ at $\mathrm{pH}$ 7.4, $60 \mathrm{~mm} \mathrm{KCl}, 15 \mathrm{~mm} \mathrm{NaCl}, 250 \mathrm{~mm}$ Sucrose, ImM EDTA, 0.1 $\mathrm{mM}$ EGTA, $0.15 \mathrm{~mm}$ spermine, and $0.5 \mathrm{~mm}$ spermidine) and $1.5 \%$ NP40. The material was homogenized in a $2-\mathrm{ml}$ Kontes dounce with the $B$ pestle. The homogenate was filtered twice through 100- $\mu$ Nitex mesh. The filtered homogenate was placed on a sucrose step gradient of $2.5 \mathrm{M}, 1.6 \mathrm{M}$, and $0.8 \mathrm{M}$ sucrose and centrifuged for $20 \mathrm{~min}$ at $20,000 \mathrm{~g}$. After centrifugation the sucrose gradient was removed and the pellet was resuspended in nuclear isolation buffer. DAPI $\left(4^{\prime}, 6\right.$-diamidino-2-phenylindole) was added to the homogenate at a concentration of $0.5 \mu \mathrm{g} / \mathrm{ml}$. Nuclei were stored on ice before analysis using a Coulter EPICS 752 flow cytometer.

\section{Slot-blot analysis and Southern hybridizations}

DNA isolation from sorted ovary or disc nuclei, blotting, and hybridization were as described in Heck and Spradling (1990). DNA samples were denatured by the addition of 0.1 volume of $3.3 \mathrm{M} \mathrm{NaOH}$ for $20 \mathrm{~min}$ at room temperature and subsequently neutralized by the addition of an equal volume of $2 \mathrm{M}$ ammonium acetate. Samples were applied in triplicate to a Nylon membrane (Nytran) using the Schleicher and Schuell minifold II slot-blot system. A minimum of two duplicate slot-blots were made using each set of samples. The filters were hybridized with either a heterochromatic probe (1.688 satellite, $\mathrm{rDNA}$ ) or a 
euchromatic probe (P1 clones) oligolabeled with $\left(\alpha^{-32} \mathrm{P}\right) \mathrm{dCTP}$. The 1.688 satellite sequence was from the plasmid pDM23 described in Lohe and Brutlag (1986). The rDNA plasmid Y22 is described in Endow and Glover (1979). P1 clones were obtained from the Drosophila Genome Project (Berkeley, CA) from regions 70A (DS00334, DS4746) and 23C (DS08704). Signal was quantified using a Molecular Dynamic PhosphoImage SF.

Plasmid rescue of the $f_{S}(2) 01672 P$ element was performed as described in Yue and Spradling (1992). Plasmid DNA was digested with the appropriate enzymes and electrophoresed on a $0.8 \%$ agarose Tris Acetate gel. DNA was transferred to GeneScreen (Dupont) membrane in the presence of $0.4 \mathrm{M} \mathrm{NaOH}$. Hybridizations were carried out as described above. A cycE type II cDNA (Richardson et al. 1993) was used as probe.

\section{Immunohistochemistry and Western blot analysis}

Ovaries were dissected, fixed, and immunologically stained and mounted as described in Lin et al. (1994). The monoclonal antibody $8 \mathrm{~B} 10$ against CycE was provided by Helena Richardson (University of Adelaide, Australia) and used at a dilution of 1:5 (Richardson et al. 1995). The monoclonal antibody against cyclin A, A19, and the monoclonal antibody against cyclin B, F24F, were provided by Pat $O^{\prime}$ Farrell and used at a concentration of 1:4. Secondary FITC-conjugated AffilPure antimouse antibodies were purchased from Jackson ImmunoResearch Laboratories (Bar Harbor, ME) and were used at a dilution of 1:200. Nuclei were counter-stained with propidium iodide as described in Orsulic and Peifer (1994) with a few modifications. Ovaries were treated for $2 \mathrm{hr}$ with $100 \mu \mathrm{g} / \mathrm{ml}$ RNase A. Subsequently, the samples were incubated for $20 \mathrm{~min}$ with $5 \mu \mathrm{g} / \mathrm{ml}$ propidium iodide and for $10 \mathrm{~min}$ with $0.5 \mu \mathrm{g} / \mathrm{ml}$ DAPI.

Western analysis was performed using a $1: 8$ dilution of the monoclonal antibody $8 \mathrm{~B} 10$. The secondary HRP-conjugated antimouse antibodies (Amersham) were used at a dilution of 1 : 5000. An enhanced-chemiluminescence kit (Amersham) was used to detect the HRP conjugate.

\section{BrdU labeling}

Ovaries were dissected in Grace's medium (Gibco BRL) and incubated in $1 \mu \mathrm{g} / \mathrm{ml} \mathrm{BrdU}$ (Sigma) diluted in Grace's medium. After a $1 \mathrm{hr}$ incubation at room temperature, the ovaries were rinsed with EBR to remove excess BrdU and fixed for $15 \mathrm{~min}$ as described above. The fixed ovaries were denatured in $2 \mathrm{M} \mathrm{HCl}$ for $30 \mathrm{~min}$ and neutralized in $100 \mathrm{~mm}$ borax for $2 \mathrm{~min}$. The ovaries were rinsed several times with PBS before being incubated overnight with a 1:20 dilution of mouse anti-BrdU (Becton-Dickinson). FITC-conjugated secondary antibody was applied as described above.

For the hs-cycE and hs-cycA experiments, females containing the transgenes and appropriate controls were placed at $37^{\circ} \mathrm{C}$ for $30 \mathrm{~min}$. After a 3-hr recovery, ovaries were dissected and labeled with BrdU.

\section{Acknowledgments}

M.L. was a fellow of the American Cancer Society. Research expenses were defrayed in part by National Institutes of Health grant GM27875 to A.C.S. We are grateful to James Flook of the Johns Hopkins Oncology Department Flow Cytometry Center for his assistance. We thank Helena Richardson for providing monoclonal anti-CycE antibody and $c y c E$ cDNA, and Pat $\mathrm{O}^{\prime}$ Farrell for providing anti-cyclinA and anti-cyclinB antibodies. We are grateful to Larry Zipursky and Christian Lehner for sending the hs-CycE and hs-CycA strains. We thank Brian Calvi, Pernille Rorth, Joe Gall, and Vincent Guacci for comments on the manuscript.
The publication costs of this article were defrayed in part by payment of page charges. This article must therefore be hereby marked "advertisement" in accordance with 18 USC section 1734 solely to indicate this fact.

\section{References}

Amon, A., M. Tyers, B. Futcher, and K. Nasmyth. 1993. Mechanisms that help the yeast cell cycle clock tick: G2 cyclins transcriptionally activate $\mathrm{G} 2$ cyclins and repress G1 cyclins. Cell 74: 993-1007.

Anderson, K. 1995. One signal, two body axes. Science 269: 489-490.

Beckingham K. and N. Thompson. 1982. Under-replication of intron ${ }^{+}$rDNA cistrons in polyploid nurse cell nuclei of Calliphora erythrocephala. Chromosoma 87: 177-196.

Belikoff, E.J. and K. Beckingham. 1985. A stochastic mechanism controls the relative replication of equally competent ribosomal RNA gene sets in dipteran polyploid nuclei. Proc. Natl. Acad. Sci. 82: 5045-5049.

Berg, C. and A. Spradling. 1991. Studies on the rate and sitespecificity of $P$ element transposition. Genetics 127:515524.

Broek, D., R. Bartlett, K. Crawford, and P. Nurse. 1991. Involvement of $\mathrm{p} 34^{\mathrm{cdc} 2}$ in establishing the dependency of $\mathrm{S}$ phase on mitosis. Nature 349: 388-393.

Carpenter, A.T.C. 1975. Electron microscopy of meiosis in Drosophila melanogaster females. I. Structural arrangement and temporal change of the synaptonemal complex in wildtype. Chromosoma 51: 157-182.

Castrillon., P. Gocnzy, S. Alexander, R. Rowson, C.G. Eberhart, S. Viswanathan, S. DiNardo, and S.A. Wasserman. 1993. Towards a molecular genetic analysis of spermatogenesis in Drosophila melanogaster. Characterization of male-sterile mutants generated by single $P$ element mutagenesis. Genetics 135: 489-505.

Clark, K.A. and D.M. McKearin. 1996. The Drosophila stonewall gene encodes a putative transcription factor essential for germ cell development. Development 122: 937-950.

Dahmann, C., J.F.X. Diffley, and K.A. Nasmyth. 1995. S-phasepromoting cyclin-dependent kinases prevent re-replication by inhibiting the transition of replication origins to a prereplicative state. Curr. Biol. 5: 1257-1269.

Dulic, V., E. Lees, and S.I. Reed. 1992. Association of human cyclin $\mathrm{E}$ with a periodic $\mathrm{G}_{1}-\mathrm{S}$ phase protein kinase. Science 257: 1958-1961

Duronio R.J. and P.H. O'Farrell. 1995. Developmental control of the $G_{1}$ to $S$ transition in Drosophila: Cyclin $E$ is a limiting downstream target of E2F. Genes \& Dev. 9: 1456-1468.

Endow, S. and J.G. Gall. 1975. Differential replication of satellite DNA in polyploid tissues of Drosophila virilis. Chromosoma 50: 175-192.

Endow, S.A. and D.M. Glover. 1979. Differential replication of ribosomal gene repeats in polytene nuclei of Drosophila. Cell 17: 597-605.

Fangman, W. and B. Brewer. 1992. A question of time: Replication origins of eukaryotic chromosomes. Cell 71: 363-366.

The FlyBase Consortium. 1994. FlyBase: The Drosophila database. Nucleic Acids Res. 22: 3456-3458.

Gage, L.P. 1974. The polyploidization of the silk gland of Bombyx mori. J. Mol. Biol. 86: 97-108.

Gall, J.G., E.H. Cohen, and M.L. Polan. 1971. Repetitive DNA sequences in Drosophila. Chromosoma 33: 319-344.

Glaser, R.L., G.H. Karpen, and A.C. Spradling. 1992. Replication forks are not found in a Drosophila minichromosome demonstrating a gradient of polytenization. Chromosoma 
102: $15-19$

Guadagno, T.M., M. Ohtsubo, J.M. Roberts, and R.K. Assoian. 1993. A link between cyclin A expression and adhesion-dependent cell cycle progression. Science 262: 1572-1575.

Hand, R. 1978. Eucaryotic DNA: Organization of the genome for replication. Cell 15: 317-325.

Hammond, M.P. and C.D. Laird. 1985. Chromosome structure and DNA replication in nurse and follicle cells of Drosophila melanogaster. Chromosoma 91: 267-278.

Hawkins, N.C., I. Thorpe, and T. Sch81pbach. 1996. encore: A gene required for the regulation of germ line mitosis and oocyte differentiation during Drosophila oogenesis. Development 122: 281-290.

Hayles, J., D. Fisher, A. Woollard, and P. Nurse. 1994. Temporal order of $\mathrm{S}$ phase and mitosis in fission yeast is determined by the state of the p34 ${ }^{\text {cdc2 }}$-mitotic B cyclin complex. Cell 78: 813-822.

Heck, M.M.S. and A.C. Spradling. 1990. Multiple replication origins are used during Drosophila chorion gene amplification. J. Cell Biol. 110: 903-914.

Heichman, K.A. and J.M. Roberts. 1994. Rules to replicate by. Cell 79: 557-562.

Heitz, E. 1934. Uber alpha and beta-Heterochromatin sowie Konstanz und Bau der Chromomeren bei Drosophila. Biol. Zbl. 54: 588-609.

Hennig, W. and U. Meer. 1971. Reduced polyteny of ribosomal RNA cistrons in giant chromosomes of Drosophila hydeii. Nat. New Biol. 233: 70-72.

Hochstrasser, M. and J.W. Sedat. 1987. Three-dimensional organization of Drosophila melanogaster interphase nuclei I. Tissue-specific aspects of polytene nuclear architecture. I. Cell Biol. 104: 1455-1470.

Karpen, G.H. and A.C. Spradling. 1992. Analysis of subtelomeric heterochromatin in the Drosophila minichromosome Dp1187 by single-P-element insertional mutagenesis. $G e$ netics 132: 737-53.

Kim-Ha, J., J.L. Smith, and P.M. Macdonald. 1991. oskar mRNA is localized to the posterior pole of the Drosophila embryo. Cell 66: 23-35.

King, R.C. 1970. Ovarian development in Drosophila melanogaster. Academic Press, New York, NY.

Knoblich, J.A. and C.F. Lehner. 1993. Synergistic action of Drosophila cyclins A and B during the G2-M transition. $E M B O$ J. 12: 65-74.

Knoblich, J.A., K. Sauer, L. Jones, H. Richardson, R. Saint, and C. Lehner. 1994. Cyclin E controls S phase progression and its down regulation during Drosophila embryogenesis is required for the arrest of cell proliferation. Cell 77: 107-120.

Koch, E.A. and R.H. Spitzer. 1983. Multiple effects of colchicine on oogenesis in Drosophila: Induced sterility and switch of potential oocyte to nurse-cell developmental pathway. Cell Tissue Res. 228: 21-32.

Koff, A., A. Giordano, D. Desai, Y. Katsumi, J.W. Harper, S. Elledge, T. Nishimoto, D.O. Morgan, B.R. Franza, and F.M. Roberts. 1992. Formation and activation of a cyclin E-cdk2 complex during the Gl phase of the human cell cycle. Science 257: 1689-1694.

Lehner, C.F. and P.H. O'Farrell. 1990a. Drosophila cdc2 homologs: A functional homolog is coexpressed with a cognate variant. $E M B O$ I. 9: 3573-3581.

- 1990b. The roles of Drosophila cyclins A and B in mitotic control. Cell 61: 535-547.

Lin, H., L. Yue. and A. Spradling. 1994. The Drosophila fusome, a germline-specific organelle, contains membrane skeletal proteins and functions in cyst formation. Development 120: $947-956$.
Lohe, A.R. and D.L. Brutlag. 1986. Multiplicity of satellite DNA sequences in Drosophila melanogaster. Proc. Nat. Acad. Sci. 83: $696-700$.

Mahowald, A. P. and M.P. Kambysellis. 1980. Oogenesis. In The genetics and biology of Drosophila (ed. M. Ashburner and T.R.F. Wright), Vol. 2, pp. 141-224. Academic Press, New York, NY.

Mahowald, A. P. and J.M. Strassheim. 1970. Intercellular migration of centrioles in the germarium of Drosophila melanogaster. I. Cell Biol. 45: 306-320.

Moreno, S. and P. Nurse. 1994. Regulation of progression through the G1 phase of the cell cycle by the rum $1^{+}$gene. Nature 367: 236-242.

Nakamura, H., T. Morita, and C. Sato. 1986. Structural organization of replicon domains during DNA synthetic phase in the mammalian nucleus. Exp. Cell Res. 165: 291-297.

Nazimiec, M. and K. Beckingham. 1986. 3B55: A repetitious sequence family which is transcribed and proportionately replicated in germ-line polyploid nuclei of Calliphora erythrocephala. Dev. Biol. 115: 398-406.

Nurse, P. 1994. Ordering S phase and M phase in the cell cycle. Cell 79: 547-550.

Ohtsubo, M. and J.M. Roberts. 1993. Cyclin-dependent regulation of G1 mammalian fibroblasts. Science 259: 1908-1912.

Orsulic, O. and M. Peifer. 1994. A method to stain nuclei of Drosophila for confocal microscopy. BioTechniques 16: $441-444$.

Resnitzky, D., M. Gossen, H. Bujard, and S.I. Reed. 1994. Acceleration of the Gl/S transition by expression of cyclins D1 and $\mathrm{E}$ using an inducible system. Mol. Cell. Biol. 14: 16691679.

Richardson, H.E., L.V. O'Keefe, S.I. Reed, and R. Saint. 1993. A Drosophila $G_{1}$-specific cyclin $E$ homolog exhibits different modes of expression during embryogenesis. Development 119: 673-690.

Richardson, H., L.V. O'Keefe, T. Marty, and R. Saint. 1995. Ectopic cyclin $E$ expression induces premature entry into $S$ phase and disrupts formation in the Drosophila eye imaginal disc. Development 121: 3371-3379.

Rudkin, G. 1972. Replication in polytene chromosomes. In Results and problems in cell differentiation (ed. W. Beerman), Vol. 4, pp. 59-85. Springer-Verlag, New York, NY.

Sauer, K., J.A. Knoblich, H. Richardson, and C.F. Lehner. 1995. Distinct modes of cyclin $\mathrm{E} / \mathrm{cdc} 2 \mathrm{c}$ kinase regulation and S-phase control in mitotic and endoreduplication cycles of Drosophila embryogenesis. Genes \& Dev. 9: 1327-1339.

Smith, A.V. and T.L. Orr-Weaver. 1991. The regulation of the cell cycle during Drosophila embryogenesis: The transition to polyteny. Development 112: 997-1008.

Spierer, A. and P. Spierer. 1984. Similar level of polyteny in bands and interbands of Drosophila giant chromosomes. $\mathrm{Na}$ ture 307: 176-178.

Spradling, A. 1993. Developmental genetics of oogenesis. In Drosophila development (ed. M. Bate and A. MartinezArias|, pp. 1-70. Cold Spring Harbor Press, Cold Spring Harbor, NY.

Spradling, A.C. and T. Orr-Weaver. 1987. Regulation of DNA replication during Drosophila development. Ann. Rev. Genet. 21: 373-403.

Stern, B., G. Ried, N.J. Clegg, T.A. Grigliatti, and C.F. Lehner. 1993. Genetic analysis of the Drosophila cdc2 homolog. Development 117: 219-232.

Storto, P.D. and R.C. King. 1989. The role of polyfusomes in generating branched chains of cystocytes during Drosophila oogenesis. Dev. Genet. 10: 70-86.

$\mathrm{Su}$, T.T., P.J. Follette, and P.H. O'Farrell. 1995. Qualifying for 
the license to replicate. Cell 81: 825-828.

Suter, B. and R. Steward. 1991. Requirement for phosphorylation and localization of the Bicaudal-D protein in Drosophila oocyte differentiation. Cell 67: 917-926.

Suter, B., L. Romberg, and R. Steward. 1989. Bicaudal-D, a Drosophila gene involved in developmental asymmetry: Localized transcript accumulation in ovaries and sequence similarity to myosin heavy chain tail domain. Genes \& Dev. 3: 1957-1968.

Theurkauf, W.E., B.M. Alberts, Y.N. Jan, and T.A. Jongens. 1993. A central role for microtubules in the differentiation of Drosophila oocytes. Development 118: 1169-1180.

Whitfield, W., C. Gonzalez, G. MacDonald-Codina, and D. Glover. 1990. The A- and B-type cyclins of Drosophila are accumulated and destroyed in temporally distinct events that define separable phases of the G2-M transition. EMBO I. 9: 2563-2572.

Yue, L. and A.C. Spradling. 1992. hu-li tai shao, a gene required for ring canal formation during Drosophila oogenesis, encodes a homolog of adducin. Genes \& Dev. 6: 2443-2454.

Zacharias, H. 1979. Underreplication of a polytene chromosome arm in the Chironomid Prodiamesa olivacea. Chromosoma 72: $23-51$.

Zhang, P. and A.C. Spradling. 1995. The Drosophila salivary gland chromocenter contains highly polytenized subdomains of mitotic heterochromatin. Genetics 139: 659-670.

Zhimulev, I.F., V.F. Semeshin, V.A. Kulichkov, and E.S. Belyaeva. 1982. Intercalary heterochromatin in Drosophila. I. Localization and general characteristics. Chromosoma 87: $197-228$. 


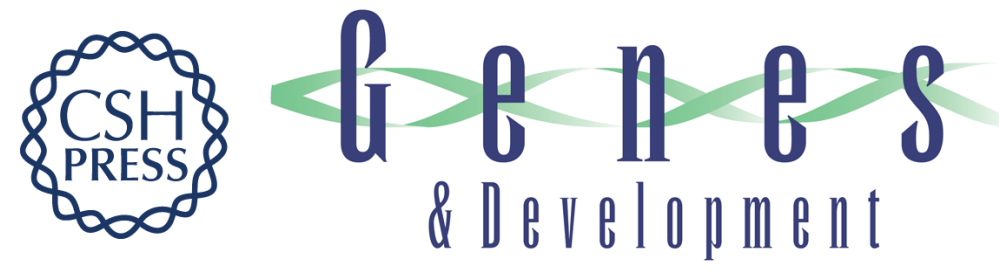

\section{The Drosophila endocycle is controlled by Cyclin E and lacks a checkpoint ensuring S-phase completion.}

M A Lilly and A C Spradling

Genes Dev. 1996, 10:

Access the most recent version at doi:10.1101/gad.10.19.2514

References This article cites 64 articles, 27 of which can be accessed free at:

http://genesdev.cshlp.org/content/10/19/2514.full.html\#ref-list-1

License

Email Alerting

Service

Receive free email alerts when new articles cite this article - sign up in the box at the top right corner of the article or click here.

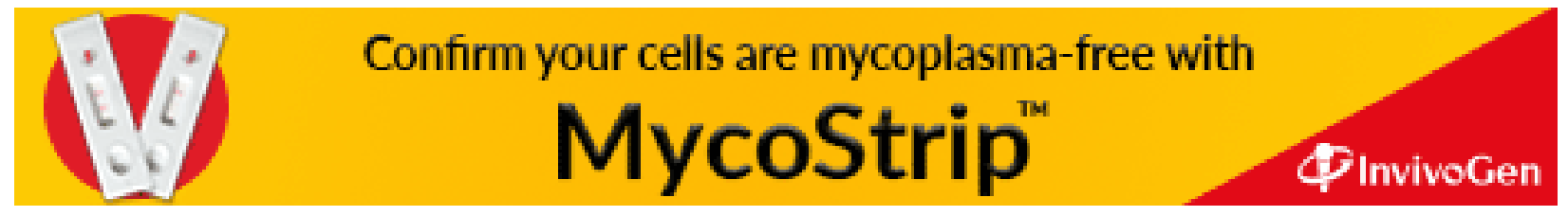

